catalogs, either in card form or in bibliographies, should be made by subject specialists to fit special needs. These catalogs should be compiled cooperatively after the needs are systematically determined.

(2) Subjective impressions of reference and circulation librarians should be given some consideration in determining cataloging policies, but they should be critically appraised by administrators and catalogers. Too many policies of an encyclopedic, bibliographical, or biographical nature have been introduced because of occasional or supposedly potential demands.
(3) Classification is primarily a librarian's device. As such, the acceptance of one system, preferably one based on a living collection of books, seems the effective procedure for the future. Both period cataloging and period classification should be systematically experimented with for selection of the preferred form.

(4) We cannot expect the program of cooperative and centralized cataloging and classification to be any more than empty words unless catalogers stop thinking of all sorts of reasons for not taking advantage of it.

By DAVID J. HAYKIN

\title{
Way to the Future: Cooperative and Centralized Cataloging
}

\author{
Mr. Haykin is chief, Subject Cataloging \\ Division, Library of Congress.
}

The terms cooperative cataloging and centralized cataloging appear to be perfectly clear and unambiguous. An examination of the literature, however, shows that they have a respectably long semantic history. To begin with, the term "cataloging" itself did not always have the connotation now current in library literature. Until the last three or four decades, it meant, among other things, the preparation of lists of books on different subjects and of different kinds, as well as of socalled universal catalogs, such as that of the International Institute of Bibliography in Brussels. In that sense it is, of course, synonymous with one of the present mean- ings of the word "bibliography." An examination of the Bibliography of Cooperative Cataloguing by Torstein Jahr and Adam J. Strohm offers unmistakable evidence on this point. A polemic engaged in as recently as the early I930's by the then chairman of the A.L.A. Committee on Bibliography, Ernest Cushing Richardson, and officers of the Association on the scope of the work of that committee as against that of the Committee on Cataloging, is further and more recent evidence on this point. For the purpose of the present discussion, the term "catalog" will be used in its current, very restricted sense of a list of the books in a given collection or library, or in several such libraries, without reference to limitations of subject or kind of book. 
Proceeding from this term, cooperative cataloging must refer to the production of the substance of a catalog by the joint effort of two or more libraries. This does not imply that the actual work of preparing catalog entries must be done by the cooperating libraries. If two or more libraries provided the money for a common fund used in preparing entries which are to go into their several catalogs, the undertaking could be properly described as cooperative cataloging. If the work were done at a central point it would be centralized and at the same time cooperative cataloging.

Centralized cataloging need not be cooperative. In one sense, the cataloging done in the main building of a public library system, for use there and in branch catalogs as well, is centralized, though not, strictly speaking, cooperative. Neither is the original and greater part of the cataloging of the Library of Congress cooperative, although it is surely centralized, since it is done centrally and, through the Card Division of the library, is made available to thousands of libraries to be used in their catalogs. It is not cooperative, since it is done by one library primarily for its own use, the cost of it being borne by that library out of funds provided for the purpose of preparing a catalog of its own collections. The sale of its cards is simply a service of the Library of Congress.

Our primary concern is with cooperative cataloging, its whys and wherefores, its methods and procedures, and, above all, its contribution in solving certain pressing problems of American libraries. We shall, therefore, discuss the question of centralized versus other methods of cataloging cooperatively only insofar as it is involved in the choice of the best method to be adopted.

\section{Why the Interest in Cooperative Cataloging Persists}

Why has the question of cooperative cataloging come to the fore again? Something-yes, something substantial-has already been achieved in that direction in the past ten years. Why then, at this time, do we imply that it is the "way to the future"? The answer to these questions rests on two considerations, a historical one and a practical one.

The practical aspect of the problem of cataloging rests on the fact that cataloging costs money, that, in fact, it takes a considerable portion of a library's total income. Fortunately or unfortunately, this aspect of cataloging is one which the administrator understands and can compute in terms of dollars and cents. As a basis for discussion on another occasion, it should be pointed out that the administration cannot compute the real cost of cataloging since he has no way of gauging the value of the product. In this regard, the cost of cataloging is, of course, closely bound up with the cost of reference work. $\mathrm{Be}$ that as it may, the total outlay of money for cataloging can be computed and, therefore, it is possible to determine the average cost per unit of the product, whether the latter be title cataloged, volume recorded in the library's catalog, card filed into it. In the face of a growing demand on the library for service, stationary, or relatively stationary income, and the impossibility of determining the cost of the intangible services which the library renders in providing information and guidance, it is obvious that the economics of the technical processes must be examined and ways found for doing the job at less cost, without perhaps sacrificing the quality, hence usefulness, of the product. Local economies may be effected by vari- 
ous means which catalogers understand well and administrators perhaps not well enough. In the light of the great reduction in the cost of cataloging resulting from the use of Library of Congress cards, it is obvious that one of the solutions of the problem of cost lies in cooperative cataloging.

In a country of the great size of ours, where the demand for certain books or classes of books arises simultaneously in different libraries, there is bound to be considerable duplication of book resources, the same work being acquired by many libraries at about the same time. In spite of all efforts which have been, or are likely to be, undertaken for a rational distribution of book resources in this country, duplication is likely to continue. This situation points to cooperative cataloging as an obvious way to reduce cataloging costs.

\section{Historical Consideration}

The historical consideration, which has kept cooperative cataloging a live subject of discussion, is the progress made in the direction of cooperation during the past forty years. Library of Congress cataloging is not in the strict sense of the word cooperative. However, catalog cards produced by it have for forty years helped to reduce cataloging costs, maintained a high level of quality, helped secure agreement on cataloging rules and practices, and developed methods and standards for the distribution of cards which have been centrally printed. This, as we shall see, intimately enters into the problem of cooperative cataloging. It has, moreover, led to several card printing and distribution ventures, among them the most recent and important is the one entered upon by the H. W. Wilson Company which provides at a small, uniform price a com- plete dictionary catalog set of cards for current books which stand high in popular demand.

A more direct influence in keeping cooperative cataloging in the foreground of library interest was the printing by the Library of Congress of catalog entries supplied by other libraries. For other United States government libraries this was first done in I9OI; the arrangement was extended to other American libraries in I9IO. The preparation of these entries was cooperative in the fullest sense of the word, since each participating library did its work for the benefit of all. The Library of Congress paid the cost of a certain amount of necessary revision and coordination, as well as for the printing of the cards.

The card printing activity of the $\mathrm{Li}$ brary of Congress, including the entries prepared by the Federal government libraries (forming the several so-called government series of the cards) and those prepared by the other American libraries (the so-called " $A$ " series) provided public libraries with cards for nearly all their books. It did not satisfy the needs of college and university libraries to the same extent. An investigation, carried out in I 93 I by Paul North Rice in behalf of the newly-formed Cooperative Cataloging Committee of the American Library Association, showed that the Library of Congress satisfied 72 per cent of the need of some forty such libraries for cards for books in English and about a third for books in foreign languages. As the result of the investigation a cooperative cataloging project was initiated in 1932 by the committee with the aid of a subvention from the General Education Board. This project covered new foreign books and monographs in certain scholarly series of 
publications largely in foreign languages. It continued under American Library Association auspices until July I, I940. It was then taken over by the Library of Congress and six months later merged with the old cooperative work which embraced other than government libraries. It is being carried on vigorously at the present moment and in some of its aspects will serve as a forecast of things to come in the field of cooperative cataloging.

\section{Objectives and Methods}

As brought out above, in the discussion of the persistence of the interest in cooperative cataloging, the paramount motive behind it is economic. It is resorted to and justified, properly so, I believe, because it makes it less costly to produce catalog entries. Its prime objective, therefore, is the reduction of the cost of cataloging. There are two other objectives to be pursued, one of them inevitable, the other highly desirable. The product of cooperation should maintain a high average of quality, approaching that of the best product of cataloging by an individual library. If cooperative cataloging results in cheaper, but inferior, entries, it is doomed to failure. The third objective is a negative one: cooperative cataloging must produce adequate catalog entries as quickly as they may be produced otherwise. It should be noted here that the criticism leveled against the cataloging establishment of the Library of Congress has been on the score of the delays in the production of entries, rarely if ever because the entries themselves were inadequate or not high enough in quality.

Bearing in mind these objectives, what conditions must be satisfied in order to carry out successfully a comprehensive undertaking in cooperative cataloging?
These conditions depend upon the nature of the project. If the project is one in which the cooperators merely underwrite it, the work being carried out by a separate central cataloging agency, by an auxiliary staff in an established cataloging department, or by a special staff housed in or near such a department, a satisfactory product can be secured : (a) if the staff is made up of competent specialists, each possessing an adequate knowledge of cataloging rules and practices, of works of reference, of certain fields of subject matter, of two or three major languages, and, if possible, some of the less well-known languages; (b) if there is available for its use an adequate reference collection; (c) if provision is made for printing, storage, and distribution of the cards. The quality of the product would be uniform since, in addition to staff and reference collection, all the catalogers would be under the same direction and supervision.

\section{Prepared by Individual Libraries}

If, however, the project is one in which entries are prepared by individual libraries and revised and printed centrally, a somewhat different set of conditions must be met. In the first place, agreement on all points of rule and practice must be secured. Each library must undertake only tasks to which its staff is capable of doing full justice, that is, for which its staff possesses the necessary cataloging knowledge and ability, the necessary command of subject matter and languages, and for which its reference collection and consultative personnel are adequate. Each library must bear in mind that it is cataloging not for its own use alone, but for all cooperative libraries. It must disregard local conditions, local needs, and local policies to that extent. This experience at 
the Library of Congress has shown to be very difficult to attain. The failure to satisfy this condition throws an undue burden on the staff assigned to the task of revising and coordinating the product of many libraries. It leads to inconsistency and, consequently, to dissatisfaction on the part of the libraries using the cards.

Whether the cataloging is done centrally or not, there must be an adequate distribution of the load, the financial load in case of centralized cataloging, the work load where the actual work is done by the cooperating libraries. This implies a direct correspondence between the load and the benefits derived from the cooperative effort by the individual library. No exact method for computing these benefits is, of course, possible. The number of entries which a given library buys during a given period, say one year, may be considered an adequate measure of the use made by that library of the product of cooperation. If the bookkeeping system used by the cooperative enterprise does not provide data on the number of entries bought, then the money value of the purchases would serve as a measure. To be sure, such a measure would be based upon a period preceding the current one, perhaps the preceding calendar year. Since no better measure can be secured and the same measure would be applied to all the cooperators, no serious injustice would result. What would be more difficult to determine is the price for the product of the cooperative enterprise to be paid by libraries which are not members of it. This need not be gone into at this stage of the discussion, however. The experience of the Cooperative Cataloging Committee project shows that some libraries, the larger and the most interested, do bear a disproportionate share of the load. If that cannot be avoided some method must be found to compensate the most active libraries on the basis of the ratio between their output and the benefits derived by them from the cooperative work.

\section{Cooperative Classification}

In most libraries the classification of books forms an integral part of the cataloging process. In any case, it is an important element of the cost. For classifying books covering the whole range of human knowledge, without the benefit of prior classification of the same works by another library, the cost may well average twenty-five cents a title. That has, in fact, been the experience of the decimal classification project begun in 1930 by several hundred libraries under the auspices of the American Library Association. This project belongs to the category of centralized cooperation. It was originally underwritten by the libraries, but the work has been carried on at the Library of Congress by a staff of well-qualified assistants. Because it was able to carry out its full program of classification well within the amount of money provided by the cooperators, it must be considered a successful project in every way. In 1933 it was taken over by the Library of Congress and assigned to the Card Division, on the assumption that the presence of the decimal classification numbers on the printed catalog cards increased the sales of the cards to an amount which would justify the maintenance of the project out of Card Division funds. In 1934 it went to form a section of the Cooperative Cataloging and Classification Service and late in 1940 with the internal reorganization of the Library of Congress, it became a part of the newly-formed Subject Cataloging Division. 
The experience of this project has evolved methods appropriate to cooperation in classification. It has made clear that, by its very nature, the work is limited both in scope and method. Since not all libraries use the same classification system, no one system would be useful to all libraries to the same extent for this reason alone. All libraries have stated or implied policies in classification which would nullify or reduce the value of cooperative classification to many of them. Because the intellectual background and capacity of the classifier are directly reflected in the classifying he does, distributive cooperation in classification is out of the question; the work must be done centrally. It must be done centrally also for the reason that consistency in the interpretation of books and classification system requires it. Consistency can be achieved by the employment of a well-qualified staff all working under the same supervisory officer and by the maintenance of some kind of a shelflist.

These considerations practically preclude the coupling of cooperative classification with a distributive system of cooperative cataloging. (It is questionable whether cooperators could reach general agreement on a choice of classification system or common classification policies Revision and coordination of class numbers at a central point without the books is practically out of the question. If the cataloging is done centrally, however, classification can readily form a part of the process.

\section{Cooperative Cataloging in the Future}

If we gave the imagination free reign, we could envisage a state of things in which catalog entries were either prepared at the source, that is by the publishers, or at a central bureau to which all the acquisitions of all cooperating libraries could be sent for cataloging. The bureau could have as competent a staff as any to be found in libraries at the present time. It would be large enough to include specialists in all fields of knowledge, linguists, expert catalogers. It could be housed so as to have ready access to adequate reference collections. It would, in short, be equipped to do cataloging accurate and adequate to all purposes. It would, however, be extremely unwieldy. It could not fully justify itself on economic grounds, since it would have to provide entries wanted by only two or three libraries, and the proportion of such books to the whole would be great enough to make the unit cost of cards to all libraries high. Then, there is the fundamental consideration that many libraries could not participate in such a project because of existing controls on the use of their funds, controls which would be difficult to change or remove. Furthermore, it would deprive libraries of the use of their books pending cataloging, would add transportation costs to the cost of cataloging, and would involve the same delays and time losses which now occur in large libraries for various reasons.

The best practical solution of the cataloging problem still is cooperation, not a particular form of cooperation, but a combination of features of all. Lines of direction have already been drawn in this country which make it easier to realize a fairly comprehensive program of cooperative cataloging. There is, for example, fairly complete agreement on rules of cataloging. Not by the fiat of a bureaucrat but by progressive, voluntary action, American libraries have achieved a large degree of uniformity in cataloging practices. The wide distribution of the catalog cards 
of the Library of Congress has contributed in large measure to uniformity of practice, since libraries found it desirable to follow the lead of the Library of Congress in order to have all catalog entries in their own catalogs uniform. The printing by the Library of Congress of entries prepared by other libraries was another, though less important, factor. And finally, the experience of the Library of Congress in centralized cataloging (for that is what its distribution of cards amounts to) and of the project initiated and sponsored by the Cooperative Cataloging Committee in cooperative cataloging on a distributive basis, furnish a foundation for an extension of cooperation in cataloging.

\section{L.C. Will Provide Entries}

The Library of Congress will continue to provide a large proportion of the entries for public libraries and an increasing proportion for college, university, and special libraries. May we look forward to the day when the Library of Congress would supply complete dictionary catalog sets of cards with headings printed on them? This would make it possible for libraries to get the cards into their catalogs without having to add headings and revise them.

A step in enlarging the program of cooperative cataloging has recently been taken by the cooperative cataloging project of the Library of Congress which definitely points the way to the future. The libraries of universities having presses have been asked to supply entries for the output of their presses. This is, in effect, cataloging by publishers. While it is unlikely that commercial publishers would, or could, engage in cataloging, this arrangement could be extended to all publishing agencies of institutions having libraries. This would apply to state libraries in the case of state documents, to public libraries in the case of the publications of municipalities, libraries of societies and institutions for their publications, particularly where analytical cataloging of their several serial publications is concerned.

Foreign publications, for want of which the Library of Congress does not have or does not prepare entries, could be cataloged as they are now on a cooperative basis. Machinery would have to be provided to secure the extension of the program of cataloging for this category of books, particularly the analytical cataloging of serial publications, and for the proper distribution of the cataloging load among the cooperating libraries.

\section{Extension of Distributive Work}

To be sure, this extension of distributive work presupposes the willingness and ability of the Library of Congress to expand its facilities for the revision of entries and the printing and distribution of cards. Means would then have to be provided either by the Federal government or the libraries which would be the beneficiaries of the work. The work could probably be carried on elsewhere at a large library center. A staff could be provided and a reference collection would be available as well as at the Library of Congress. The Library of Congress, however, already maintains a large nucleus for this work and has the storage and distribution facilities for large sales operations in this field. It seems inevitable, therefore, that the work be centered at the Library of Congress. Whether this would mean an expansion of the cooperative cataloging facilities there or the establishment of a

(Continued on page 175) 
tions under the present practice of the Library of Congress. There is no doubt that simple notations of these items will result in a considerable saving of time.

Additional time and study is needed at the Library of Congress on these points, but, as I have indicated, it seems certain that some simplifications can be made. It is our belief that a simplified card which will serve the needs of the Library of Congress will be adequate for other libraries. In fact, many libraries may be able to simplify their practices farther than the Library of Congress can do. When specific details have become more settled, you will be informed of the changes which the Library of Congress proposes to make. In the meantime, as Miss Root has suggested, it will be extremely helpful if individual librarians will confer with their acquisition, reference, and cataloging staffs and seek to determine what types of information are needed in the catalogs of their respective libraries. Such study is essential for the formulation of a policy in the individual library and will greatly assist the Library of Congress in modifying its own practice.

\section{Way to the Future: Cooperative and Centralized Cataloging}

\section{(Continued from page I62)}

separate unit coordinated with the cooperative work there is subject to consideration by representatives of cooperating libraries and of the Library of Congress. The Librarian of Congress has on several occasions expressed his interest in the extension of cooperative cataloging.

\section{Cooperative Work the Practical Solution of the Cataloging Problem}

To sum up, the practical solution of the cataloging problem, assuming that the catalog is not to be abolished altogether as has been recently, perhaps not too se- riously, proposed by some administrators, or reduced to a simple author list, lies in cooperative work. Cooperative cataloging should not confine itself to one particular method. Libraries should continue to make use of the cataloging product of the Library of Congress and amplify the scope of its work by some auxiliary form of either centralized or distributive cooperation. If all libraries find the H. W. Wilson Company's product adequate, the Library of Congress could perhaps be relieved of the burden of supplying cards for the most popular books. 